\title{
Evaluation of gestational diabetes mellitus risk in South Indian women based on MTHFR (C677T) and FVL (G1691A) mutations
}

\author{
Imran Ali Khan ${ }^{1,2,3}$, Noor Ahmad Shaik ${ }^{4}$, Vasundhara Kamineni ${ }^{5}$, Parveen Jahan ${ }^{3}$, \\ Qurratulain Hasan ${ }^{1,2}$ and Pragna Rao ${ }^{6 *}$ \\ ${ }^{1}$ Department of Genetics and Molecular Medicine, Kamineni Hospitals, Hyderabad, India, ${ }^{2}$ Department of Genetics, Vasavi \\ Medical and Research Center, Hyderabad, India, ${ }^{3}$ Department of Genetics and Biotechnology, Osmania University, \\ Hyderabad, India, ${ }^{4}$ Department of Genetic Medicine, Faculty of Medicine, King Abdulaziz University, Jeddah, Saudi \\ Arabia, ${ }^{5}$ Department of Gynecology and Obstetrics, Kamineni Hospitals, Hyderabad, India, ${ }^{6}$ Department of Biochemistry, \\ Kasturba Medical College, Manipal University, Manipal, Karnataka, India
}

OPEN ACCESS

Edited by:

Marijana Pericic Salihovic, Institute for Anthropological Research,

Croatia

Reviewed by:

Suresh Kumar Chitta

Sri Krishnadevaraya University, India

Shaik Abdul Nabi,

University of Hyderabad, India

Tatjana Skaric-Juric,

Institute for Anthropological Research,

Croatia

${ }^{*}$ Correspondence: Pragna Rao,

Department of Biochemistry, Kasturba Medical College, Manipal University, Manipal, Karnataka, India drpragnarao@gmail.com

Specialty section:

This article was submitted to Genetic Disorders, a section of the journal

Frontiers in Pediatrics

Received: 26 November 2014 Accepted: 07 April 2015 Published: 05 May 2015

Citation:

Khan IA, Shaik NA, Kamineni V, Jahan P, Hasan Q and Rao P (2015) Evaluation of gestational diabetes mellitus risk in South Indian women based on MTHFR (C677T) and FVL

(G1691A) mutations.

Front. Pediatr. 3:34.

doi: 10.3389/fped.2015.00034
We aimed to scrutinize the extent to which single amino acid substitutions in the MTHFR and factor $V$ Leiden (FVL) genes affect the risk of gestational diabetes mellitus (GDM) in pregnant women of South Indian descendant. This case-control study was implemented once the ethical approval has been obtained. Overall, 237 women were recruited in this study: 137 had been diagnosed with GDM and the remaining 100 women were used as normal controls or non-GDM. The diagnosis of GDM was confirmed with biochemical analysis, i.e., GCT and oral glucose tolerance tests. Five milliliters of peripheral blood was collected and used for biochemical and molecular analyses. DNA was isolated, and genotyping for MTHFR (C677T) and FVL (G1691A) mutations was performed using PCR-RFLP. FVL (G1691A) locus was not polymorphic in the investigated sample. There was no significant difference in the allele and genotype frequencies of C677T polymorphism between GDM and non-GDM women $(p=0.8892)$.

Keywords: gestational diabetes mellitus, MTHFR, FVL, C677T, G1691A

\section{Introduction}

Gestational diabetes mellitus (GDM) is among the most common metabolic disorders affecting pregnant women characterized by glucose intolerance of variable severity, which is usually detected at the onset of or during pregnancy (1). GDM is treated by insulin or dietary modifications. It typically develops during the secondary trimester of pregnancy and resolves after the delivery (2). The risk of GDM women is intensified by advanced maternal age, ancestral disparities, obesity, and a family history of diabetes (3); however, the exact etiology is unknown due to limited knowledge of genetic factors (4). GDM patients are at increased risk of gestational hypertension, pre-eclampsia during pregnancy, and type 2 diabetes (T2DM), as well as metabolic syndromes in later life (5). Pregnant women with a history of GDM are at greater risk of developing T2DM, and a family history of diabetes predisposes pregnant women to GDM (6). Elevated fasting glucose and insulin levels are observed in women who do not have GDM but have a family history of the disease (7). Individuals of Asian descents have two- to sevenfold greater risk of developing GDM than their Caucasian counterparts in developed countries (8). Various epidemiological studies have reported an association between metabolic disorders and risk of developing T2DM or GDM, and numerous 
efforts have been made to identify pathogenic mutations in nuclear and mitochondrial genomes that are linked to both types of diabetes. Various susceptibility loci have been identified by linkage analyses and genome-wide association studies (1).

The methylenetetrahydrofolate reductase (MTHFR) gene has been mapped to chromosomal region $1 \mathrm{p} 36.3$ and comprises 11 exons encoding $5^{\prime}, 10^{\prime}$-MTHFR (9), a key regulatory enzyme in folate metabolism that converts $5^{\prime}, 10^{\prime}$-MTHF to $5^{\prime}$-MTHF, the methyl donor for the remethylation of homocysteine to methionine (10). C677T is a common missense mutation in the gene that results in the substitution of alanine for valine at amino acid position 222 . The $\mathrm{A} 222 \mathrm{~V}$ mutation is associated with a $50 \%$ reduction in MTHFR enzymatic activity, which increases plasma homocysteine and decreases plasma folic acid concentrations (11, 12). The factor $V$ Leiden ( $F V L$ ) gene is involved in the blood coagulation; G1691A mutation results in the substitution of guanine with arginine at the amino acid position 506, yielding a defective FVL protein that is unable to interact with the activated protein $\mathrm{C}$, which was associated with increased coagulation activity and susceptibility to thromboembolism in previous studies. This mutation has also been linked to increased thrombosis risk and mortality in women following delivery/pregnancy $(13,14)$. Numerous studies have found an association between complications during pregnancy and inherited thrombophilias caused by mutations in MTHFR and FVL (15-17). However, there have been no studies to date addressing the potential role of MTHFR and FVL mutations in the development of GDM in the Indian population. The objective of this study was to investigate the extent to which single amino acid substitutions in the MTHFR and FVL genes affect the risk of GDM in pregnant women of South Indian descent.

\section{Materials and Methods}

\section{Ethics Statement}

The study protocol was approved by the institutional ethics committee at Kamineni hospitals. Written, informed consent was obtained from all subjects, who were recruited by a clinical research midwife.

\section{Study Subjects}

This study was carried out in South Indian population from 2007 to 2011. Study subjects were recruited from Kamineni and Muslim maternity hospitals, Hyderabad. A total of 237 pregnant women participated in the study; of these, 137 had GDM, and 100 had normal glucose levels during pregnancy (i.e., the nonGDM group). A diagnosis of GDM was made by analyzing $3 \mathrm{~mL}$ of serum samples obtained from each subject; an additional $2 \mathrm{~mL}$ of blood was collected and stored in ethylenediamine tetraacetic acid (EDTA) in order to screen for MTHFR and FVL mutations. Among GDM patients, $58.4 \%$ had a family history of T2DM. Screening and management of diabetes during pregnancy were performed by qualified gynecologists according to guidelines set by the American Diabetes Association (18).

\section{Clinical and Biochemical Analyses}

Gestational diabetes mellitus cases were identified using the glucose challenge test between weeks 24 and 28 of gestation; $50 \mathrm{~g}$ of glucose was administered to pregnant women with fasting plasma glucose levels exceeding $130 \mathrm{mg} / \mathrm{dL}$. The oral glucose tolerance test (OGTT) was then performed using $100 \mathrm{~g}$ of glucose following an overnight fast and 3 days on an unrestricted diet. Fasting plasma samples were drawn $1-3 \mathrm{~h}$ after glucose administration. In this study, GDM cases were defined as those whose glucose levels met or exceeded threshold values described by Khan et al. (19). Women diagnosed with T1DM, T2DM, or any other form of diabetes before pregnancy, were excluded from the study. Body mass index (BMI) was calculated as weight $/$ height $^{2}\left(\mathrm{~kg} / \mathrm{m}^{2}\right)$. Subjects with BMI $>25 \mathrm{~kg} / \mathrm{m}^{2}$ were identified as overweight, while a BMI $>30 \mathrm{~kg} / \mathrm{m}^{2}$ was categorized as obese. Blood samples were collected in order to measure the fasting blood sugar (FBS) early in the morning after overnight fast for more than $10 \mathrm{~h}$ and post-prandial blood glucose (PPBG) levels after $2 \mathrm{~h}$ of the FBS.

\section{DNA Extraction and Genotyping}

Genomic DNA was extracted from blood samples stored in EDTA using previously described methods (20). The DNA was dissolved in Tris-EDTA buffer at $100 \mathrm{ng} / \mu \mathrm{L}$ and stored at $-80^{\circ} \mathrm{C}$ prior to the molecular analysis. C677T (MTHFR) and G1691A $(F V L)$ mutations were screened using PCR and restriction fragment length polymorphism analysis performed with previously published primers and restriction enzymes (21) (Table 1). PCR amplification conditions were as follows; 35 cycles of denaturation at $95^{\circ} \mathrm{C}$ for $5 \mathrm{~min}$, followed by annealing at $68^{\circ} \mathrm{C}$ for $30 \mathrm{~s}(\mathrm{C} 677 \mathrm{~T})$ or $56^{\circ} \mathrm{C}$ for $30 \mathrm{~s}(\mathrm{G} 1691 \mathrm{~A})$, and extension at $72^{\circ} \mathrm{C}$ for $5 \mathrm{~min}$. PCR products were digested with appropriate restriction enzymes in a total volume of $20 \mu \mathrm{L}$ for $16 \mathrm{~h}$ at $37^{\circ} \mathrm{C}$, and analyzed by $2.5 \%$ agarose gel electrophoresis with ethidium bromide staining.

\section{Statistical Analysis}

Hardy-Weinberg equilibrium was calculated in the cases and controls as described in our prior study (22). Differences between genotype/allele frequencies of GDM and non-GDM subjects were calculated using $T$ test. The Yates correction was applied prior to analyzing genotype frequencies of MTHFR and FVL mutations. The odds ratio (OR) for genotype/phenotype relations and its $95 \%$

TABLE 1 | Details for genotyping MTHFR and FVL genes.

\begin{tabular}{|c|c|c|c|c|c|c|c|c|}
\hline Gene & $\begin{array}{c}\text { SNP } \\
\text { location }\end{array}$ & rs no. & $\begin{array}{l}\text { Amino acid } \\
\text { substitution }\end{array}$ & Forward primer & Reverse primer & Fragment & $\begin{array}{c}\text { Annealing } \\
\text { temperature }\end{array}$ & Enzyme \\
\hline MTHFR & Exon 5 & rs1801133 & Ala 222 Val & $\begin{array}{l}\text { TGAAGGAGAAGGTGT } \\
\text { CTGCGGGA }\end{array}$ & $\begin{array}{l}\text { GGACGGTGCGGTG } \\
\text { AGAGTG }\end{array}$ & 198 bp & $68^{\circ} \mathrm{C}$ & Hinfl \\
\hline FVL & Exon 10 & rs6020 & Arg 506 Gln & $\begin{array}{l}\text { TCAGGCAGGAACAA } \\
\text { CACCAT }\end{array}$ & $\begin{array}{l}\text { GGTTACTTCAAGGACAAAA } \\
\text { TACCTGTAAAGCT }\end{array}$ & $241 b p$ & $56^{\circ} \mathrm{C}$ & HindIII \\
\hline
\end{tabular}


TABLE 2 | Clinical details of GDM cases and controls.

\begin{tabular}{|c|c|c|c|c|}
\hline S. No. & Factors & GDM $(n=137)$ & Controls $(n=100)$ & $p$ Value $^{a}$ \\
\hline 1 & Age (years) & $26.7 \pm 5.1$ & $24.6 \pm 3.55$ & 0.0001 \\
\hline 2 & $\mathrm{BMl}\left(\mathrm{kg} / \mathrm{m}^{2}\right)$ & $26.8 \pm 3.93$ & $24.1 \pm 3.55$ & 0.28 \\
\hline 3 & Weight (kg) & $69.3 \pm 10.18$ & $51.2 \pm 6.26$ & 0.0001 \\
\hline 4 & Mean gestational age (weeks) & $24.4 \pm 5.0$ & NA & NA \\
\hline 5 & FBS (mg/dL) & $110.6 \pm 3.93$ & $99.24 \pm 11.37$ & $<0.0001$ \\
\hline 6 & PPBG (mg/dL) & $158.80 \pm 47.76$ & $112.00 \pm 39.70$ & 0.05 \\
\hline 7 & Family history & $80(58.4 \%)$ & $56(56 \%)$ & 0.66 \\
\hline 8 & Insulin/diet therapy $\left(R_{\mathrm{x}}\right)$ & $81(59.1 \%) / 56$ (40.9\%) & NA & NA \\
\hline
\end{tabular}

${ }^{a} t$-Test applies to calculate the $p$ value between GDM and non-GDM subjects.

NA, not analyzed/not applicable, BMI, body mass index; FBS, fasting blood sugar; PPBG, post-prandial blood glucose.

confidence interval (CI) was calculated performing chi-square test in the cross-tabs procedure for a $2 \times 2$ tables using SPSS software. All statistical analyses were performed using SPSS version 19.0 (SPSS Inc., Chicago, IL, USA).

\section{Results}

\section{Characteristics of the Study Population}

The clinical characteristics of GDM patients and non-GDM subjects are listed in Table 2. GDM cases $(n=137)$ were aged 22-38 years with a mean age of $26.7 \pm 5.1$ years, whereas the age and mean age for controls $(n=137)$ were $17-34$ and $24.6 \pm 3.55$ years. The pre-pregnancy BMI range was $19.8-35.6 \mathrm{~kg} / \mathrm{m}^{2}$ (mean: $26.8 \pm 3.93 \mathrm{~kg} / \mathrm{m}^{2}$ ) for $\mathrm{GDM}$ and $19-31.1 \mathrm{~kg} / \mathrm{m}^{2}$ (mean: $\left.24.1 \pm 3.55 \mathrm{~kg} / \mathrm{m}^{2}\right)$ for controls $(p=0.28)$; $40.9 \%$ of individuals managed the diabetes with appropriate diet therapy and exercise, while $59.1 \%$ of patients required four to eight units of insulin therapy over the entire prenatal period. Age, weight, FBS, and PPBG values differed significantly between GDM cases and controls $(p<0.05)$.

\section{C677T Allele and Genotype Frequencies}

Genotype and allele frequencies were in Hardy-Weinberg equilibrium in both groups. The PCR product encompassing the C677T mutation was 198 bp in length; digestion with HinfI ( ${ }^{\downarrow}$ ANTC) yielded 198 and 175/23 bp fragments representing $C$ and $T$ alleles, respectively (Figure 1). Genotype frequencies for C677T CC, CT, and TT among GDM cases were 81.8, 18.2, and $0 \%$, respectively. The frequencies of the $\mathrm{T}$ and $\mathrm{C}$ alleles were 9 and $91 \%$. In control subjects, the frequencies of the $\mathrm{CC}, \mathrm{CT}$, and TT genotypes were 82,18 , and $0 \%$, respectively, and $\mathrm{C}$ and $\mathrm{T}$ allele frequencies were 91 and $9 \%$. Table 3 presents just the distribution of genotypes and alleles by GDM status. There was no evidence of a disease association for any of the allelic or genotype classes (OR: $-1.015 ; 95 \% \mathrm{CI}=0.5378-1.916 ; p=0.8892$ and OR: $-1.011 ; 95 \%$ $\mathrm{CI}=0.5211-1.961 ; p=0.9746)$.

\section{G1691A Allele and Genotype Frequencies}

A 241-bp PCR product encompassing the G1691A mutation was digested with HindIII ( ${ }^{\downarrow}$ AGCTT), yielding a 209-bp fragment indicating the presence of the A allele (Figure 2). Only the GG (100\%) genotype was observed in both cases and controls; therefore, this locus was not further analyzed.

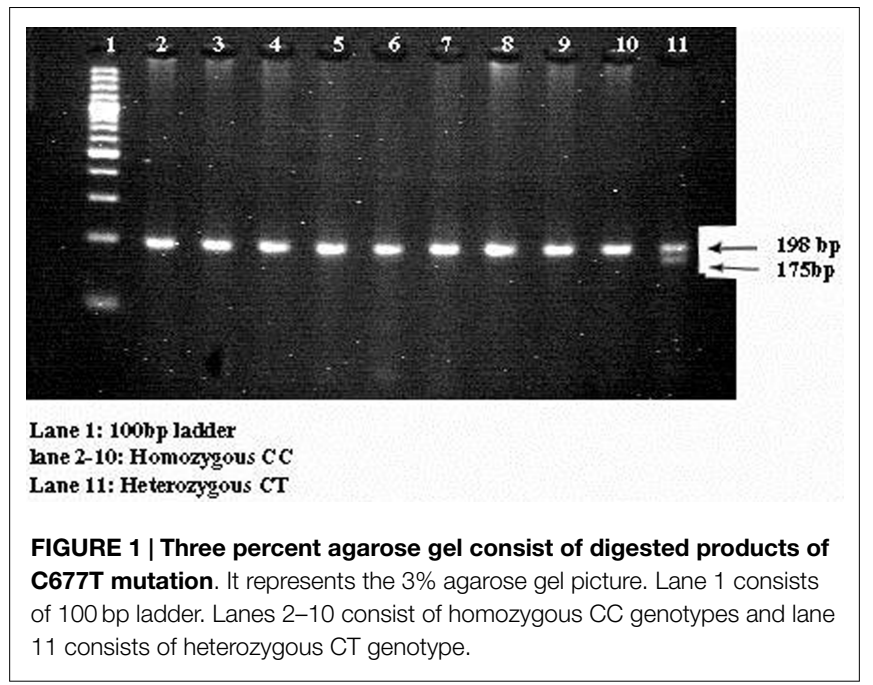

TABLE 3 | Allele and genotype frequencies in GDM cases and controls for MTHFR gene.

\begin{tabular}{lccc}
\hline Genotype and allele & $\begin{array}{c}\text { GDM cases } \\
(n=137)\end{array}$ & $\begin{array}{c}\text { Controls } \\
(n=100)\end{array}$ & $p$ Value $^{a}$
\end{tabular}

MTHFR (rs1801133)

\begin{tabular}{lccc}
\hline & $\boldsymbol{N}(\%)$ & $\boldsymbol{N}(\%)$ & \\
\hline CC & $112(81.8)$ & $82(82)$ & $0.96^{\mathrm{a}}$ \\
CT & $25(18.2)$ & $18(18)$ & \\
TT & $0(0)$ & $0(0)$ & \\
C & $249(0.09)$ & $182(91)$ & $0.96^{\mathrm{a}}$ \\
T & $25(0.09)$ & $18(9)$ & \\
\hline
\end{tabular}

${ }^{a}$ Chi-square $p$ value.

\section{Discussion}

This study investigated whether C677T and G1691A mutations are associated with the development of GDM among individuals of South Indian descent by genotyping age-matched cases and pregnant non-GDM subjects. The results did not reveal any association between investigated mutations and GDM risk in this study population.

Hyperglycemia is associated with an increased risk of unfavorable outcome in adults (T2DM), children (T1DM), and pregnant 


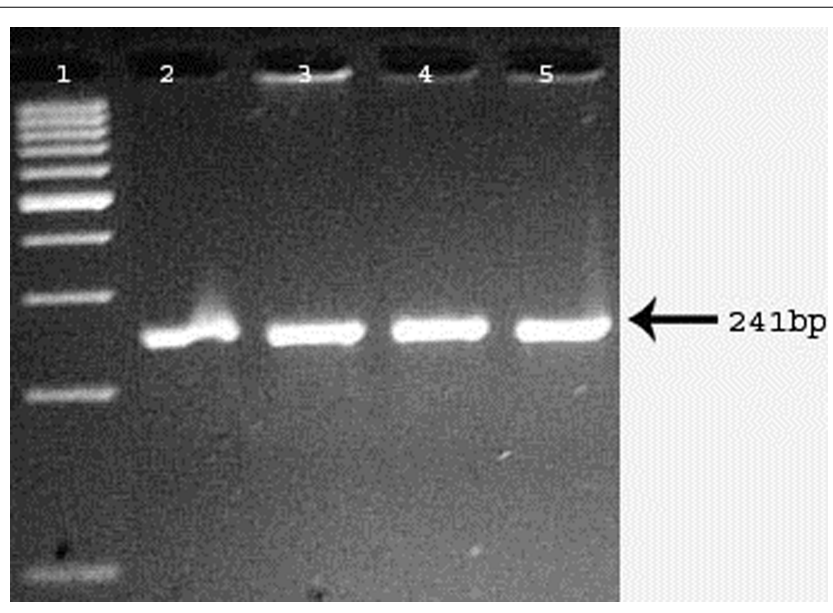

FIGURE 2 | Digested products appeared on $3 \%$ agarose gel for evaluation of FVL (G1691A) mutation. Digested PCR products run on 3\% agarose gel. Lane 1 represents 100 bp DNA ladder. Lanes 2-5 represent homozygous GG genotypes.

women (GDM) (23). MTHFR and FVL gene mutations are considered risk factors for hereditary thrombophilia and may influence the development of complications during pregnancy (24). We sought to determine whether C677T and G1691A mutations are associated with altered glucose levels during pregnancy, which could indicate GDM risk. Cases and controls differed significantly in terms of age, weight, FBS, and PPBG, but not with respect to genotype frequencies at either locus. These results suggest that the $\mathrm{C} 677 \mathrm{~T}$ and G1691A mutations are not involved in the development of GDM during pregnancy in Indian population.

The frequency of MTHFR gene mutations varies across geographical and ethnic groups. For example, the frequency of C677T in T2DM cases fluctuates between 40 and 49\%, depending on the ethnicity of the study cohort (India, 40\%; Turkey, 49\%; Tunisia, 45\%; Brazil, 46\%; and China, 44\%) (25-29). The C677T genotype frequencies (CC and CT) between north (25) and South Indian populations in T2DM and GDM subjects are varied. Both environmental and genetic factors contribute to the development and progression of GDM during pregnancy; this work showed that MTHFR mutations have no role in GDM in South Indian population.

\section{References}

1. Khan IA, Shaik NA, Pasupuleti N, Chava S, Jahan P, Hasan Q, et al. Screening of mitochondrial mutations and insertion-deletion polymorphisms in gestational diabetes mellitus in Asian Indian population. Saudi J Biol Sci (2015). doi:10. 1016/j.sjbs.2014.11.001

2. Huidobro A, Prentice A, Fulford T, Parodi C, Rozowski J. Gestational diabetes, comparison of women diagnosed in second and third trimester of pregnancy with non GDM women: analysis of a cohort study. Rev Med Chil (2010) 138:316-21. doi:10.4067/S0034-98872010000300009

3. Lappas M. GSK3 $\beta$ Is increased in adipose tissue and skeletal muscle from women with gestational diabetes where it regulates the inflammatory response. PLoS One (2014) 9:e115854. doi:10.1371/journal.pone.0115854
The prior report from Australian population confirmed that $16.6 \%$ women harboring the MTHFR C677T gene mutation developed at least one pregnancy complication; however, the effect was restricted to women with small for gestational age (SGA) infants. There were no differences in genotype distribution among women with intrauterine fetal death, pre-eclampsia, or preterm delivery, and the study concluded that the mutation was a genetic marker for identifying women who are at increased risk of having an SGA infant (30).

Diabetes is a risk factor for thrombotic events (31) and atherothrombosis (32). The pathogenesis of diabetes involves hypercoagulability of the blood due to several factors such as the non-enzymatic glycosylation of clotting inhibitors. Patients who are carriers of a thrombophilic gene variant (e.g., factor $\mathrm{V}$ A $1691 \mathrm{G}$ and $\backslash$ or prothrombin A20210G) or other thrombotic risk factors are susceptible to the inherited or acquired thrombophilia. FVL mutations lead to a thrombophilic condition that is heritable both in hetero- and homozygous forms (33). Several previous studies have investigated a potential relationship between $F V L$ gene mutations and diabetes incidence, and there is one report of a possible co-segregation of $F V L$ and T2DM risk alleles (34).

A prevalence of $4.6 \%$ for the A allele of FVL G1691A (rs6020) has been reported among coronary artery disease patients with T2DM (35). In a later study, these authors reported prevalence rates for this mutation of 3.2, 1.6, and 4.9\% among Iranian T2DM patients, T2DM patients with microalbuminuria, and normoalbuminuric T2DM patients, respectively, suggesting that the FVL G1691A mutation is not associated with microalbuminuria in this population (14). This mutation has also been implicated in the pathogenesis of thrombosis (36).

No association was found between FVL mutations and T2DM among Lebanese (36), Dutch (37), Japanese (38), and Caucasian patients (39).

In conclusion, MTHFR (C677T) and FVL (G1691A) mutations are not likely to be genetic risk factors for the development of GDM in South Indian women.

\section{Acknowledgments}

Gratitude is expressed to all the volunteers who have participated in this study. We are grateful to Indian Council for Medical Research for providing SRF to IAK and funding of this research (Sanction no. 5-3-8-39-2007; RHN).

4. Khan AI, Jahan P, Hasan Q, Rao P. Angiotensin-converting enzyme gene insertion/deletion polymorphism studies in Asian Indian pregnant women biochemically identifies gestational diabetes mellitus. J Renin Angiotensin Aldosterone Syst (2014) 15:566-71. doi:10.1177/1470320313502106

5. Zhang C, Tobias DK, Chavarro JE, Bao W, Wang D, Ley SH, et al. Adherence to healthy lifestyle and risk of gestational diabetes mellitus: prospective cohort study. BMJ (2014) 30:349. doi:10.1136/bmj.g5450

6. Al-Hakeem MM, Abotalib Z, Alharbi KK, Khan IA. Insertion and deletion polymorphism in the alpha-2B adrenoceptor gene in pregnant women ripens gestational diabetes mellitus. Saudi J Biol Sci (2015). doi:10.1016/j.sjbs.2014.11. 010

7. Gunderson EP, Chiang V, Pletcher MJ, Jacobs DR, Quesenberry CP, Sidney S, et al. History of gestational diabetes mellitus and future risk of atherosclerosis in 
mid-life: the Coronary Artery Risk Development in Young Adults study. J Am Heart Assoc (2014) 3:e000490. doi:10.1161/JAHA.113.000490

8. Ping F, Xiang HD, Li M, Li W, Liu JT, Nie M, et al. Effects of variation in retinol binding protein 4gene and adipose specific expression of gestational diabetes Beijing, China. Diabetes Res Clin Pract. (2012) 97:283-9. doi:10.1016/j.diabres. 2012.02.017

9. Rai V. Folate pathway gene MTHFR C677T polymorphism and risk of lung cancer in Asian populations. Asian Pac J Cancer Prev (2014) 15:9259-64. doi:10. 7314/APJCP.2014.15.14.5853

10. Liu NB, Li J, Qi JF, Zhang ZZ, Wu X, Zhang JH. Methylenetetrahydrofolate reductase 677TT genotype may be associated with an increased lung cancer risk in North China: an updated meta-analysis. Med Sci Monit (2014) 20:2817-23. doi:10.12659/MSM.892050

11. Cadenas-Benitez NM, Yanes-Sosa F, Gonzalez-Meneses A, Cerrillos L, Acosta D, Praena-Fernandez JM, et al. Association of neural tube defects in children of mothers with MTHFR 677TT genotype and abnormal carbohydrate metabolism risk: a case-control study. Genet Mol Res (2014) 13:2200-7. doi:10. 4238/2014.March.26.8

12. Xuan C, Li H, Zhao JX, Wang HW, Wang Y, Ning CP, et al. Association between MTHFR polymorphisms and congenital heart disease: a meta-analysis based on 9,329 cases and 15,076 controls. Sci Rep (2014) 4:7311. doi:10.1038/srep07311

13. Lippi G, Mattiuzzi C, Cervellin G. Meta-analysis of factor V Leiden and prothrombin G20210A polymorphism in migraine. Blood Coagul Fibrinolysis (2015) 26:7-12. doi:10.1097/MBC.0000000000000188

14. Rahimi Z, Felehgari V, Rahimi M, Mozafari H, Yari K, Vaisi-Rayagani A, et al. The frequency of factor V Leiden mutation, ACE gene polymorphism, serum ACE activity and response to ACE inhibitor and response to ACE inhibitor ana angiotensin II receptor antagonist drugs in Iranians type II diabetic patients with microalbuminuria. Mol Biol Rep (2011) 38:2117-23. doi:10. 1007/s11033-010-0338-1

15. Parveen F, Shukla A, Agrawal S. Should factor V Leiden mutation and prothrombin gene polymorphism testing be done in women with recurrent miscarriage from North India? Arch Gynecol Obstet (2013) 287:375-81. doi:10.1007/ s00404-012-2557-2

16. Aggarwal S, Dimri N, Tandon I, Agarwal S. Preeclampsia in North Indian women: the contribution of genetic polymorphisms. J Obstet Gynaecol Res (2011) 37:1335-41. doi:10.1111/j.1447-0756.2010.01523.x

17. Zahed LF, Rayes RF, Mahfouz RA, Taher AT, Maarouf NH, Nassar AH. Prevalence of factor V Leiden, prothrombin and methylene tetrahydrofolate reductase mutations in women with adverse pregnancy outcomes in Lebanon. Am J Obstet Gynecol (2006) 195:1114-8. doi:10.1016/j.ajog.2006.06.082

18. American Diabetes Association. Diagnosis and classification of diabetes mellitus. Diabetes Care (2011) 34:S62-9. doi:10.2337/dc11-S062

19. Khan IA, Movva S, Shaik NA, Chava S, Jahan P, Mukkavali KK, et al. Investigation of Calpain 10 (rs2975760) gene polymorphism in Asian Indians with gestational diabetes mellitus. Meta Gene (2014) 2:299-306. doi:10.1016/j.mgene. 2014.03.001

20. Khan IA, Jahan P, Hasan Q, Rao P. Relation between PTEN gene and gestational diabetes women in Asian Indians. J Health Special (2015) 1:18-22. doi:10.1016/ j.jrhm.2015.01.001

21. Alharbi KK, Khan IA, Syed R. Thrombophilic gene polymorphism studies in G6PD deficient individuals from Saudi population. Bioinformation (2012) 8:1255-9. doi:10.6026/97320630081255

22. Khan IA, Vattam KK, Jahan P, Mukkavali KK, Hasan Q, Rao P. Correlation between KCNQ1 and KCNJ11 gene polymorphisms and type 2 and posttransplant diabetes mellitus in the Asian population. Genes Diseases (2015). doi:10.1016/j.gendis.2015.02.009

23. Seaquist ER, Oz G. Diabetes: does lactate sustain brain metabolism during hypoglycaemia? Nat Rev Endocrinol (2013) 9:386-7. doi:10.1038/nrendo.2013. 104

24. Mierla D, Szmal C, Neagos D, Cretu R, Stoian V, Jardan D. Association of prothrombin (A20210G) and factor V Leiden (A506G) with recurrent pregnancy loss. Maedica (Buchar). (2012) 7:222-6.

25. Raza ST, Abbas S, Ahmed F, Fathima J, Zaidi ZH, Mahdi F. Association of MTHFR and PPAR $\gamma 2$ gene polymorphisms in relation to type 2 diabetes mellitus cases among north Indian population. Gene (2012) 15:375-9. doi:10. 1016/j.gene.2012.09.072

26. Errera FI, Silva ME, Yeh E, Maranduba CM, Folco B, Takahashi W, et al. Effect of polymorphisms of the MTHFR and APOE genes on susceptibility to diabetes and severity of diabetic retinopathy in Brazilian patients. Braz J Med Biol Res (2006) 39:883-8. doi:10.1590/S0100-879X2006000700005

27. Mtiraoui N, Zammiti W, Ghazouani L, Braham NJ, Saidi S, Finan RR, et al. Methylenetetrahydrofolate reductase C677T and A198C polymorphism and changes in homocysteine concentrations in women with idiopathic recurrent pregnancy losses. Reproduction (2006) 131:395-401. doi:10.1530/rep.1.00815

28. Sun JZ, Xu Y, Lu H, Zhu Y. Polymorphism of the methylenetetrahydrofolate reductase gene association with homocysteine and ischemic stroke in type 2 diabetes. Neurol India (2009) 57:589-93. doi:10.4103/0028-3886.57808

29. Yilmaz H, Agachan B, Ergen A, Karaalib ZE, Isbir T. Methylenetetrahydrofolate reductase C677T mutation and left ventricular hypertrophy in Turkish patients with type II diabetes mellitus. J Biochem Mol Biol (2004) 37:234-8. doi:10.5483/ BMBRep.2004.37.2.234

30. Stonek F, Hafner E, Philipp K, Hefler LA, Bentz EK, Tempfer CB. Methylenetetrahydrofolate reductase $\mathrm{C} 677 \mathrm{~T}$ polymorphism and pregnancy complications. Obstet Gynecol (2007) 110:363-8. doi:10.1097/01.AOG.0000270122.13198.6f

31. Fumelli P, Romagnoli F, Carlino G, Fumelli C, Boemi M. Diabetes mellitus and chronic heart failure. Arch Gerontol Geriatr (1996) 23:277-81. doi:10.1016/ S0167-4943(96)00736-4

32. Kannel WB, McGee DL. Diabetes and cardiovascular disease (1979). The Framingham study. JAMA (1979) 241:2035-8. doi:10.1001/jama.1979. 03290450033020

33. Lodigiani C, Ferrazzi P, Di Micco P, Libre L, Genovese S, Quaglia I, et al. Is there a relationship between factor V Leiden and type 2 diabetes? J Transl Med. (2009) 7:52. doi:10.1186/1479-5876-7-52

34. Krekora K, De Lucia D, Capani F, Donati MB, Iacoviello L. Association of coagulation factor VArg506Gln mutation with non-insulin-dependent diabetes mellitus. Lancet (1996) 348:1666-7. doi:10.1016/S0140-6736(05)65740-6

35. Rahimi Z, Nomani H, Mozafari H, Vaisi-Raygani A, Madani H, Malek-Khosravi S, et al. Factor V G1691A, prothrombin G20210A and methylenetetrahydrofolate reductase polymorphism C677T are not associated with coronary artery disease and type 2 diabetes mellitus in western Iran. Blood Coagul Fibrinolysis (2009) 20:252-6. doi:10.1097/MBC.0b013e3283255487

36. Wakim-Ghorayeb SF, Keleshian SH, Timson G, Finan RR, Najm P, IraniHakime N, et al. Factor V G1691A (Leiden) and prothrombin G20210A singlenucleotide polymorphisms in type 2 diabetes mellitus. Am J Hematol (2005) 80:84-6. doi:10.1002/ajh.20406

37. Hart LM, De Knijff P, Dekker JM, Stolk RP, Nijpels G, Van der Does FE, et al. Variants in the sulphonylurea receptor gene: association of the exon 16-3t variant with Type II diabetes in Dutch Caucasians. Diabetologia (1999) 42:617-20. doi:10.1007/s001250051203

38. Odawara M, Yamashita K. Factor V Leiden mutation and Japanese NIDDM. Diabetologia (1997) 40:1363-4. doi:10.1007/s001250050833

39. Finan RR, Tamin H, Ameen G, Sharida HE, Rashid M, Almawi WY. Prevalence of factor V G16191A (factor V-Leiden) and prothrombin G20210A gene mutations in a recurrent miscarriage population. Am J Hematol (2002) 71:300-5. doi:10.1002/ajh.10223

Conflict of Interest Statement: The authors declare that the research was conducted in the absence of any commercial or financial relationships that could be construed as a potential conflict of interest. The Review Editor Suresh Kumar Chitta declares that, despite having collaborated on a publication in the last 2 years with author Noor Ahmad Shaik, the review process was handled objectively.

Copyright (C) 2015 Khan, Shaik, Kamineni, Jahan, Hasan and Rao. This is an openaccess article distributed under the terms of the Creative Commons Attribution License (CC BY). The use, distribution or reproduction in other forums is permitted, provided the original author(s) or licensor are credited and that the original publication in this journal is cited, in accordance with accepted academic practice. No use, distribution or reproduction is permitted which does not comply with these terms. 